\title{
Associations among the Components of the East Asian Summer Monsoon System in the Meridional Direction
}

\author{
Riyu LU \\ Institute of Atmospheric Physics, Chinese Academy of Sciences, Beijing, China
}

(Manuscript received 29 November 2002, in final form 4 November 2003)

\begin{abstract}
The East Asian summer monsoon is characterized by strong interactions among its components in the meridional direction. The atmospheric convection over the Philippine Sea (PSAC), the western North Pacific subtropical high (WNPSH) and the East Asian westerly jet stream (EAJ) are all closely related to the summer rainfall in East Asia. In this study, we examined the relationship on the interannual timescale among these factors, by using the National Centers for Environmental Prediction/National Center for Atmospheric Research (NCEP/NCAR) Re-analysis data and satellite-observed outgoing long-wave radiation (OLR) data for the 20-year period from 1979 to 1998.

It is found that the PSAC-EAJ relation is weak in June, but strong in July and August. Similar difference exists in the relationship between the PSAC and convective activity along the East Asian summer rainy belt. Corresponding to enhanced PSAC, the EAJ is weakened in July and strengthened in August, and tends to exhibit a slight poleward displacement in both months. All these variations in the EAJ intensity and meridional displacement, on the other hand, correspond to suppressed convection along the East Asian summer rainy belt. Finally, the monthly difference in the PSAC-EAJ relation is interpreted by the role of vertical shear of zonal wind. The easterly shear in July and August over the Philippine Sea excites external modes, which are necessary for the tropical-extratropical teleconnection mechanism according to previous numerical studies, but the neutral shear in June is inefficient in exciting external modes.
\end{abstract}

\section{Introduction}

Unlike the South Asian summer monsoon, the East Asian summer monsoon is characterized by strong interactions among its components in the meridional direction (Wang et al. 2001). The East Asian summer monsoon system includes the monsoon trough in the tropics, the western North Pacific subtropical high (hereafter WNPSH), Meiyu or Baiu front, and the disturbances in the middle latitudes (Tao and Chen 1987). The relationship between the rainfall along the Meiyu/Baiu front and other

Corresponding author: Riyu Lu, Institute of Atmospheric Physics, Chinese Academy of Sciences, PO Box 2718, Beijing 100080, China.

E-mail: lr@lasg.iap.ac.cn

(C) 2004, Meteorological Society of Japan monsoon components has been highlighted in various previous studies, since the rainfall has great economic and climatic importance for the half billion people living in the Yangtze River and Huaihe River basin, Korean peninsula, and southern and central Japan.

A seesaw relationship in convective activity between the tropical western Pacific and East Asia was identified (Nitta et al. 1986; Nitta 1987; Huang and $\mathrm{Li}$ 1987). It was suggested that the anomalous convective activities over the tropical western Pacific trigger an atmospheric Rossby wave that propagates from the tropics poleward to extratropics (Nitta 1987; Huang and Li 1987; Kurihara and Tsuyuki 1987).

The WNPSH also plays a crucial role in influencing the summer rainfall in East Asia. In 
general, the WNPSH advances poleward and retreats eastward in summer, and dominates the large-scale location and intensity of rainfall in East Asia. Lu (2002) defined two indices to depict the interannual variability of WNPSH in the zonal and meridional directions, respectively. His results indicate that a westward extended or an equatorward shifted WNPSH corresponds to heavier rainfall along the East Asian rainy belt in summer.

The East Asian jet stream (EAJ) is a dominant feature of the extratropical circulation in upper troposphere over East Asia. The EAJ is intimately related to rainfall in China (e.g., Liang and Wang 1998). In summer, an equatorward EAJ displacement accompanies increased precipitation over south-central China, while a poleward shift is associated with heavier rainfall in North China.

The convection over the tropical western $\mathrm{Pa}$ cific may be considered as the most crucial one among the above-mentioned factors, since it acts as a major heating source. In fact, it is intimately associated with the seasonal evolution and interannual variation of location and intensity of WNPSH (Kurihara and Kawahara 1986; Kurihara and Tsuyuki 1987; Huang and Li 1987; Kurihara 1989). When the convection over the tropical western North Pacific is enhanced, the WNPSH appears over South Japan with a barotropic structure, that is, the WNPSH exhibits a poleward displacement. Recently, Lu and Dong (2001) showed that the convection over the tropical western North Pacific also significantly influences the interannual variation of zonal location of the WNPSH.

Furthermore, the convection over the tropical western Pacific appears to affect the circulation in the middle latitudes and even over North America (Nitta 1987; Huang and Sun 1992; Wang et al. 2001). This association between the tropical convection and the extratropical circulation, however, depends on subseasonal period. Tsuyuki and Kurihara (1989) divided summer into rainy season (May 26 to July 14) and mid-summer season (July 15 to September 2 ), and found that the tropical convection is not strongly related to the midlatitude flow over East Asia during the rainy season, and there are no definite indicators that the tropical convection forces the midlatitude flow. During the mid-summer season, in contrast, the convective activity around the Philippines and the IndoChina Peninsula has a significant impact on the East Asian atmospheric circulation.

In the present study, more evidence is given for the associations in the meridional direction among the factors that are closely related to the rainfall variability in East Asia. The associations in each month of summer, as well as in summer as a whole, are examined, respectively. Finally, a possible mechanism for the subseasonal difference in the tropical-extratropical linkage is given. The relation among the PSAC, WNPSH, EAJ and East Asian convective activity on the interannual timescale is examined in section 2. A possible mechanism responsible for the sub-seasonal change in the meridional associations is presented in section 3 . Section 4 is devoted to summary.

\section{Sub-seasonal difference in the interannual relationship}

In this study, we use the National Centers for Environmental Prediction/National Center for Atmospheric Research (NCEP/NCAR) Reanalysis data for the 20-year period from 1979 to 1998. Kalnay et al. (1996) gave a full description of the re-analysis project. The model is run at T62 spectral resolution in the horizontal with 28 levels in the vertical. We also use the National Oceanic and Atmospheric Administration (NOAA) satellite-observed outgoing long-wave radiation (OLR) data for the same period (Gruber and Krueger 1984). The climatology represents the average over this period, and monthly mean data are used in this study.

In this study, the Philippine Sea is defined as the region $\left(110-160^{\circ} \mathrm{E}, 10-20^{\circ} \mathrm{N}\right)$, which is identical to that of Wu and Wang (2001) and of $\mathrm{Lu}$ (2001). The year-to-year standard deviation of JJA mean OLR is relatively larger over this region ( $\mathrm{Lu} \mathrm{2001).} \mathrm{Furthermore,} \mathrm{the} \mathrm{year-to-}$ year deviation in each month of summer is also relatively larger over the region, as well as over the belt of $0 \sim 15^{\circ} \mathrm{S}$ (Fig. 1). The region of larger deviation extends eastward over the Philippine Sea from June to August, but basically remains at identical latitudes, despite the fact that the climatological enhanced convection shifts poleward during late summer.

Figure 2 shows the interannual variations of June, July, August and JJA mean OLR 
Standard Deviation of OLR

(o) June

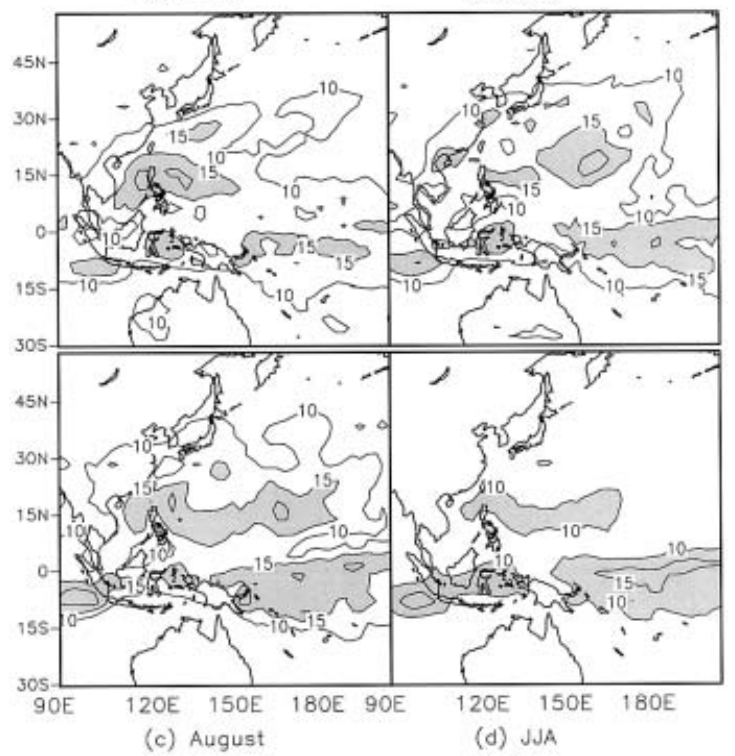

Fig. 1. Year-to-year standard deviation of OLR in June (a), July (b), August (c), and JJA (d). Contour interval is $5 \mathrm{Wm}^{-2}$, and the values larger than $15 \mathrm{Wm}^{-2}$ are shaded. The contour line of 5 is not shown for the sake of clarity.

anomalies averaged over the Philippine Sea, respectively. We chose the years in which the absolute values of the OLR anomalies are greater than half of standard deviation, and performed composite analyses based on these years. For JJA mean, for instance, the years with a greater OLR (weak convection) are 1979, 1980, 1983, 1987, 1993, 1995, 1996 and 1998 (8 years), and the years with a less OLR (strong convection) are 1981, 1984, 1985, 1986, 1989, 1990 and 1994 (7 years).

There are differences among these chosen years for June, July, August and JJA mean OLR. The years chosen according to June OLR are somewhat similar to those according to August or JJA OLR. However, the years that are chosen as weak (strong) convection according to July OLR even appear as strong (weak) convection years according to June, August or JJA OLR.

\subsection{PSAC and convective activity over the East Asian rainy belt}

Based on the interannual variations of PSAC, we perform a composite analysis for

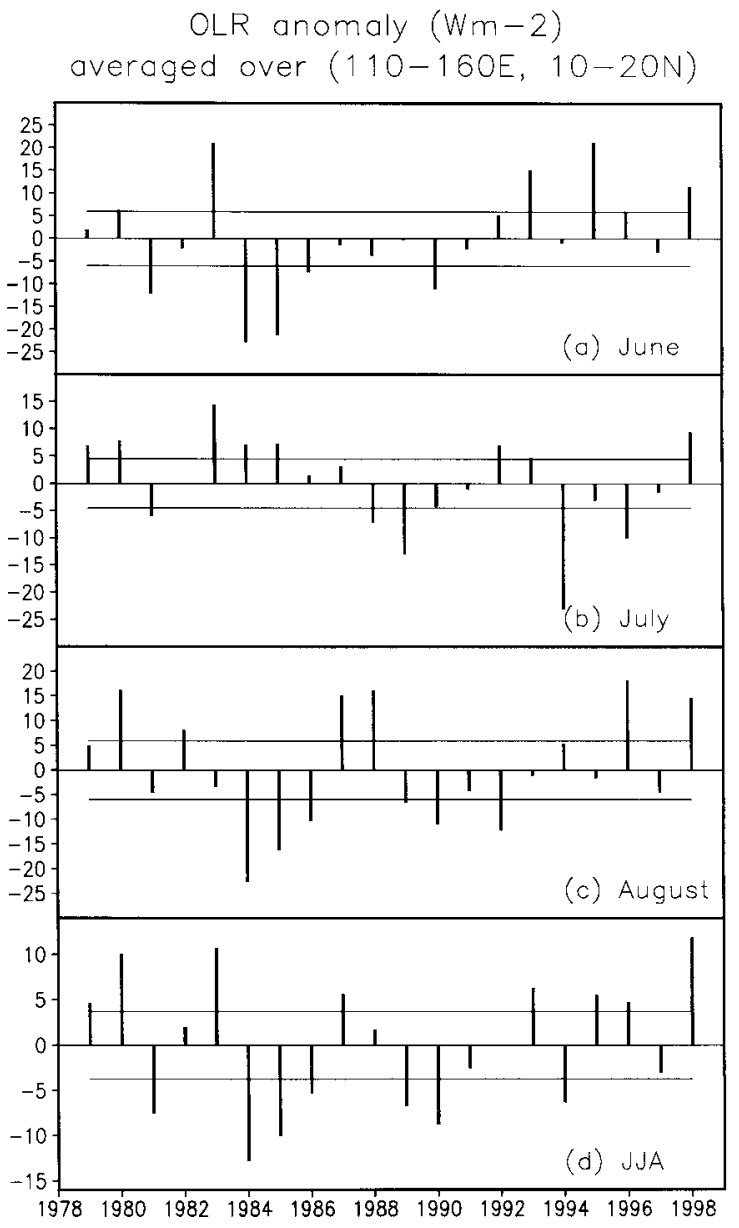

Fig. 2. Interannual variations of June (a), July (b), August (c), and JJA (d) mean OLR anomalies averaged over the Philippine Sea $\left(110-160^{\circ} \mathrm{E}, 10-20^{\circ} \mathrm{N}\right)$. The lines of half standard deviations of the anomalies are also given. Unit is in $\mathrm{Wm}^{-2}$. The ordinate indicates the values of OLR anomalies, and the abscissa indicates the years.

each month of summer, in attempt to highlight the sub-seasonal difference in the associations of convection.

Figure 3 shows the composite differences in OLR between the strong and weak PSAC years chosen by June, July, August and JJA mean OLR, respectively. These OLR differences generally exhibit a similar distribution, that is, convection is significantly enhanced over the Philippine Sea, and is suppressed along the southwest-northeast oriented rainy belt in East 
OLR Diff. (strong-weak convection) (o) June (b) July

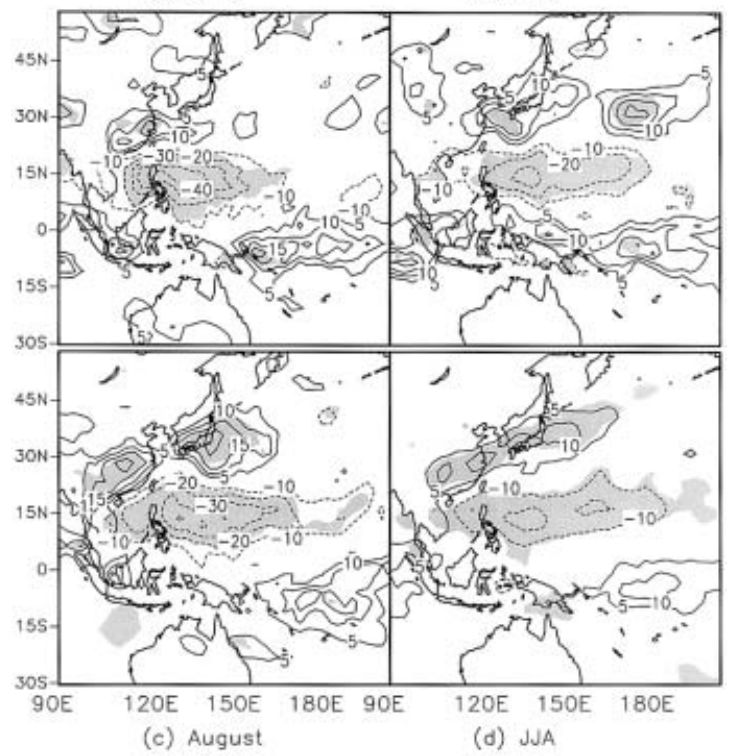

Fig. 3. Composite differences in OLR between the strong and weak PSAC years chosen by June (a), July (b), August (c), and JJA (d) mean OLR, respectively. The shading illustrates the statistical significance of the differences at the 95\% level determined from the twosided Student's t-test. Zero contour is not shown for the sake of clarity. Contour interval is $5 \mathrm{Wm}^{-2}$ for positive values and is $10 \mathrm{Wm}^{-2}$ for negative values.

Asia. The intensity of convection differences over the Philippine Sea is weaker in July, compared to that in June and August. The JJA mean OLR differences are in relatively smaller values but with higher statistical significance levels. The OLR differences along the East Asian rainy belt are smallest and in the lowest statistical significance level in June.

\subsection{PSAC and WNPSH}

The differences in $850-\mathrm{hPa}$ geopotential heights exhibit slight but appreciable changes from month to month (Fig. 4), despite the similar distribution of convection differences over the Philippine Sea among individual months. In June, strong PSAC corresponds to significant negative anomalies of $850-\mathrm{hPa}$ geopotential heights over the tropical western Pacific
$850 \mathrm{hPa}$ Height Diff. (strong-weak convection)

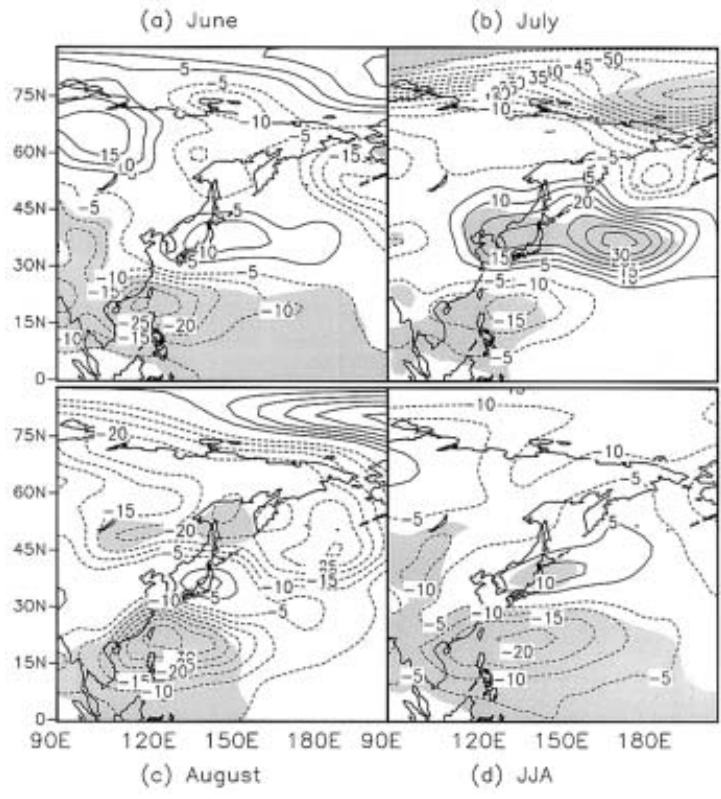

Fig. 4. Same as Fig. 3, but for $850-\mathrm{hPa}$ geopotential heights. Contour interval is $5 \mathrm{gpm}$, and zero contour is not shown.

and South China Sea (Fig. 4a). There are positive anomalies over the Korean Peninsula and Japan and the subtropical western Pacific, but with a statistical significance level lower than 95\%. Over Northeast Asia, negative anomalies appear and do not reach the 95\% significance level. The significant height differences are confined in the low latitudes in June. In July, the negative anomalies around the Philippines are smaller, but still significant, while the positive anomalies over the Korean Peninsula and Japan and the subtropical western Pacific are much greater and significant (Fig. 4b). The height anomalies in August exhibit a similar distribution with those in June, but the negative anomalies over Northeast Asia are somewhat significant (Fig. 4c). In JJA, significant negative height anomalies appear over the tropical western Pacific and South China Sea, and positive anomalies over Japan (Fig. 4d).

These $850-\mathrm{hPa}$ height anomalies indicate the differences in WNPSH between strong and weak PSAC. In each month and in JJA, the WNPSH exhibits a remarkable eastward and 
$200 \mathrm{hPa}$ Zonal Wind Diff. (strong-weak convection)

(o) June

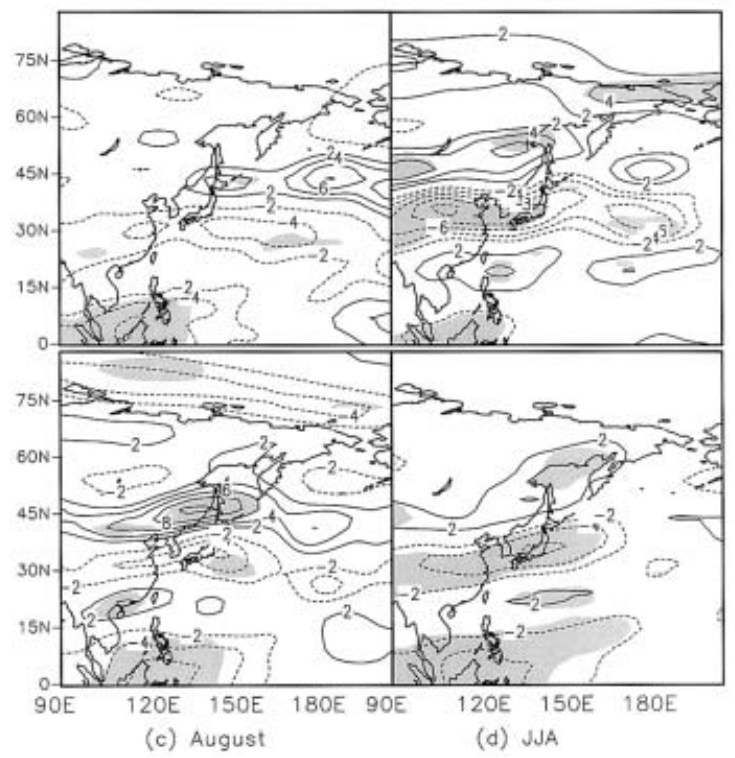

Fig. 5. Same as Fig. 3, but for 200-hPa zonal wind. Contour interval is $2 \mathrm{~m} \mathrm{~s}^{-1}$, and zero contour is not shown.

slight poleward displacement when the PSAC is enhanced (not shown).

\subsection{PSAC and EAJ}

Figure 5 shows the differences in the 200$\mathrm{hPa}$ zonal wind between strong and weak PSAC. Although in each month and in JJA, the westerly flow basically decreases along $35^{\circ} \mathrm{N}$ and increases along $45^{\circ} \mathrm{N}$, the intensity and significance level show a considerable change from month to month. In the middle latitudes, the differences in zonal wind are not significant in June, and are significant in both July and August. However, weakened westerly along $35^{\circ} \mathrm{N}$ and strengthened westerly along $45^{\circ} \mathrm{N}$ are dominant in July and in August, respectively. In JJA, there are significant negative anomalies over Southeast China, South Korea and the central and southern Japan (Fig. 5d). North to these regions, there are also positive anomalies. Like the differences in $850-\mathrm{hPa}$ geopotential heights, the significant differences in $200-\mathrm{hPa}$ zonal wind are also confined in the low latitudes in June, but appear as a wavelike pattern in the middle latitudes in July and August and in JJA mean.

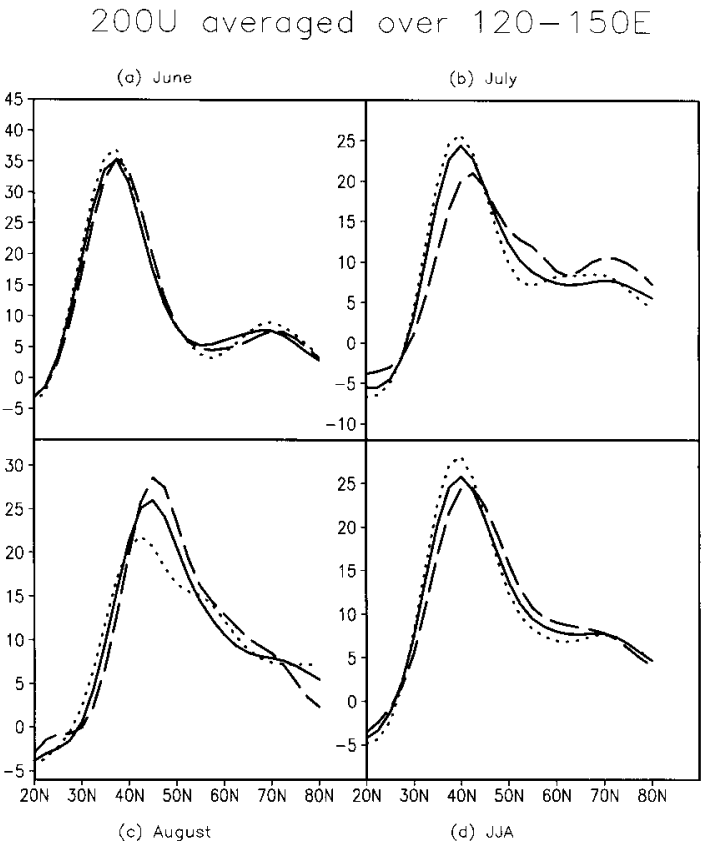

Fig. 6. Composite 200-hPa zonal wind averaged over $120-150^{\circ} \mathrm{E}$ for strong (dashed line) and weak (dot line) PSAC years chosen by June (a), July (b), August (c), and JJA (d) mean OLR, respectively. The climatological mean (solid line) is also given. Unit in the ordinate is in $\mathrm{m} \mathrm{s}^{-1}$.

Corresponding to simultaneous strong PSAC, the EAJ is weakened in July but strengthened in August (Fig. 6), although the $200-\mathrm{hPa}$ zonal wind differences show a similar distribution in these two months (Figs. 5b and 5c). Climatologically, the EAJ is located approximately along $37.5^{\circ} \mathrm{N}$ in June and shifts poleward to $40^{\circ} \mathrm{N}$ in July and to $45^{\circ} \mathrm{N}$ in August (Fig. 7). Therefore, the core of EAJ corresponds to negative anomalies in July but to positive anomalies in August. Fig. 6 also shows that the EAJ tends to exhibit a poleward displacement when the PSAC is strong in July or August or JJA. In June, the EAJ only shows a very slight change in its intensity, while its core remains in the same meridional place.

\subsection{EAJ and convective activity along the East Asian rainy belt}

In the preceding subsection, it has been shown that the PSAC anomaly corresponds to both the intensity change and meridional dis- 


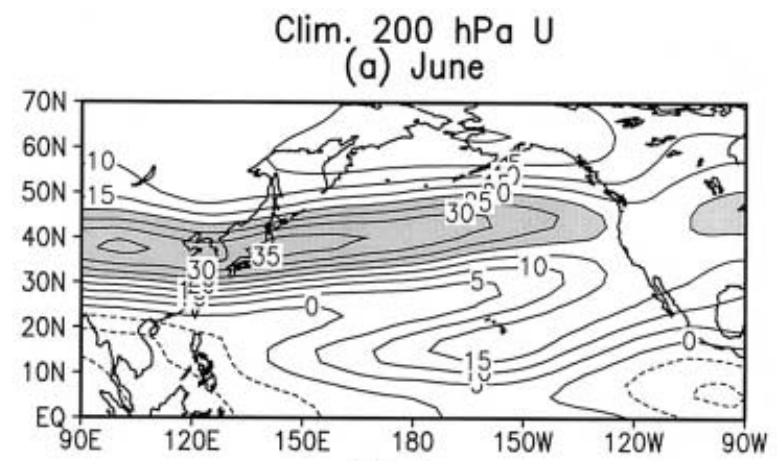

(b) July

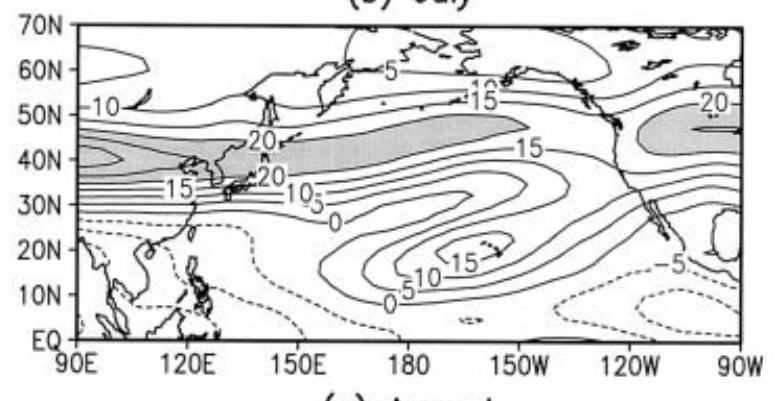

(c) August

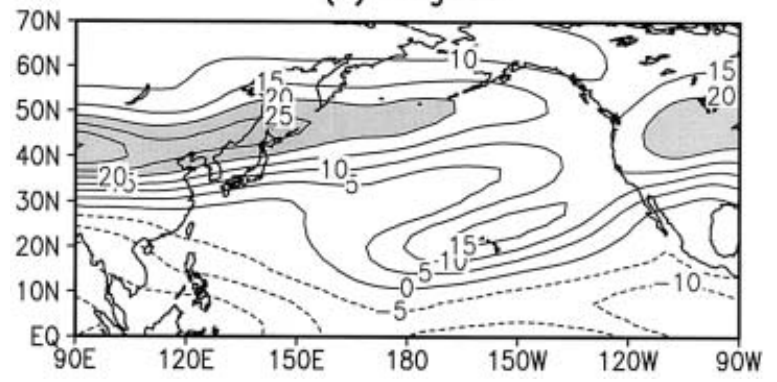

Fig. 7. Climatological zonal wind at 200 $\mathrm{hPa}$ in June (a), July (b) and August (c). The values larger than $20 \mathrm{~m} \mathrm{~s}^{-1}$ are shaded. Contour interval is $5 \mathrm{~m} \mathrm{~s}^{-1}$.

placement of EAJ. In this subsection, we will examine the East Asian convection anomalies associated with these two aspects of EAJ variations, respectively.

Figure 8 shows the correlation coefficients between the interannual variations of EAJ intensity and OLR. The EAJ intensity is defined as the $200-\mathrm{hPa}$ zonal winds averaged over the latitudes between 5 degrees poleward of and 5 degrees equatorward of the EAJ core, and over the longitudes of $120-150^{\circ} \mathrm{E}$, same as those in Fig. 6. The latitudes of the EAJ core are set to $37.5^{\circ} \mathrm{N}, 40^{\circ} \mathrm{N}, 45^{\circ} \mathrm{N}$ and $40^{\circ} \mathrm{N}$ for June, July, August and JJA, respectively (Figs. 6 and 7). In

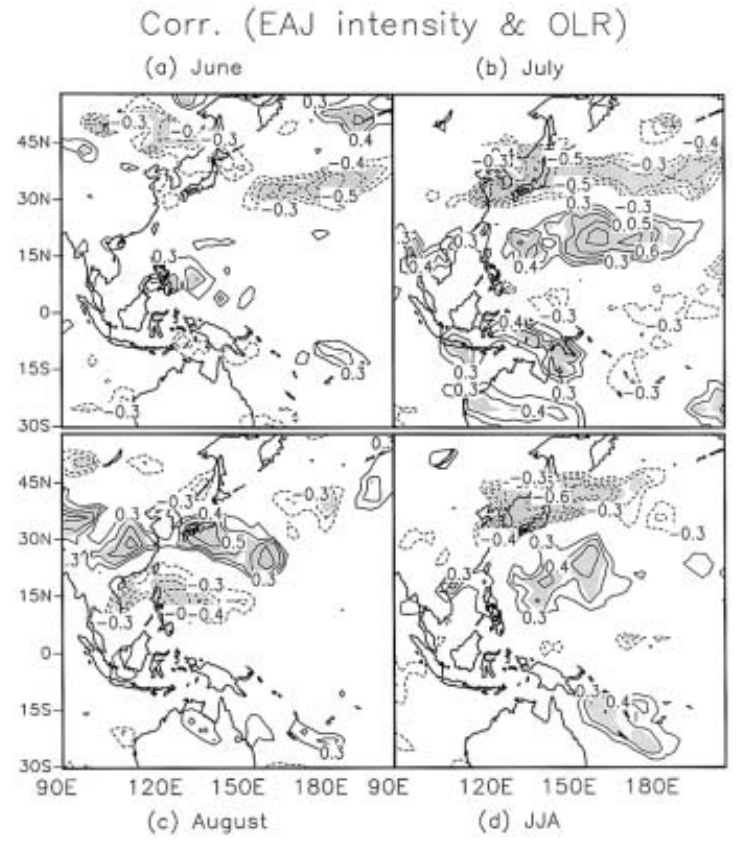

Fig. 8. Correlation coefficients between the EAJ intensity and OLR at each grid point in June (a), July (b), August (c), and JJA (d). The EAJ intensity is defined as the 200-hPa zonal wind averaged over the longitudes of $120-150^{\circ} \mathrm{E}$ and the latitudes between 5 degrees poleward of and 5 degrees equatorward of the EAJ core that is set to $37.5^{\circ} \mathrm{N}$, $40^{\circ} \mathrm{N}, 45^{\circ} \mathrm{N}$ and $40^{\circ} \mathrm{N}$ for June, July, August and JJA, respectively. Contour interval is 0.1 , but the lines of $0, \pm 0.1$ and \pm 0.2 are not shown. The shading illustrates the statistical significance of 95\% level.

June, the correlation coefficients are negative in Northeast Asia and weakly negative in Korea and Japan, and are positive with a slight significance in the Philippine Sea (Fig. 8a). In July, they exhibit a clear dipole distribution in the western North Pacific and East Asia, being negative in East Asia and positive in the western North Pacific (Fig. 8b). There is a similar dipole distribution in August, but with opposite signs (Fig. 8c). The distribution of JJA correlation coefficients is similar to that of July.

Interestingly, a stronger EAJ corresponds to enhanced convection in East Asia in July (Fig. 8b), but to suppressed convection in $\mathrm{Au}-$ 
gust (Fig. 8c). In addition, a stronger EAJ corresponds to suppressed convection in the tropical western North Pacific in July (Fig. 8b), but to enhanced convection in August (Fig. 8c). Therefore, this contrary between July and August correlation patterns shown in Fig. 8 is helpful for the seesaw relationship in convective activity between the tropical western North Pacific and East Asia.

The year-to-year standard deviation of 200$\mathrm{hPa}$ zonal wind is relatively larger exactly poleward and equatorward of EAJ in each month of summer (Fig. 9), indicating that the meridional displacement is a dominant feature of interannual variability of EAJ. Figure 9 also shows that the EAJ exhibits a larger meridional displacement in July and August, with more evidence from the fact that the EAJ is remarkably stronger in June than that in July and August (Fig. 7).

Figure 10 shows the correlation coefficients between the meridional displacement of EAJ and OLR at each grid point. The meridional displacement of EAJ is represented by the difference between the $200-\mathrm{hPa}$ zonal winds averaged over the two regions: 10 degrees poleward and equatorward of the EAJ core within the longitude of $120-150^{\circ} \mathrm{E}$. For instance, the meridional displacement of July EAJ is determined by the difference between the $200-\mathrm{hPa}$ zonal winds averaged over $\left(120-150^{\circ} \mathrm{E}, 40-\right.$ $\left.50^{\circ} \mathrm{N}\right)$ and $\left(120-150^{\circ} \mathrm{E}, 30-40^{\circ} \mathrm{N}\right)$.

A poleward shifted EAJ is significantly related to positive OLR anomalies along the East Asian summer rainy belt, and to negative OLR anomalies over the tropical western North Pacific, in each month and in JJA (Fig. 10). In particular, the correlation between the meridional displacement of EAJ and convection along the East Asian rainy belt is quite high. Different approaches to depict the meridional displacement of EAJ lead to very slight differences in correlation coefficients along the East Asian summer rainy belt, indicating that the EAJ-East Asian convection relation on the interanuual timescale is robust.

In Fig. 10, the suppressed convection shifts poleward with month and exactly follows the East Asian rainy belt, which clearly shifts poleward with time during summer. That is, in June the suppressed convection appears to the south of Japan, in July over the Yangtze River

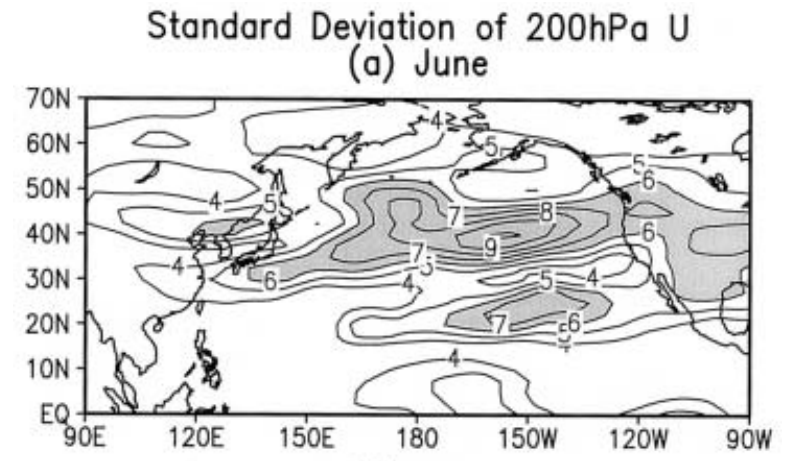

(b) July

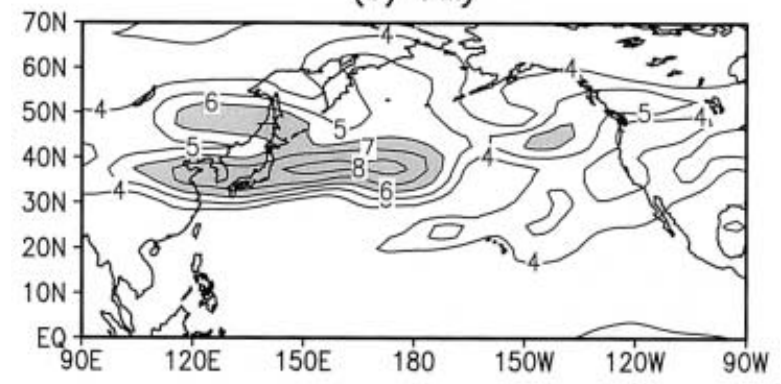

(c) August

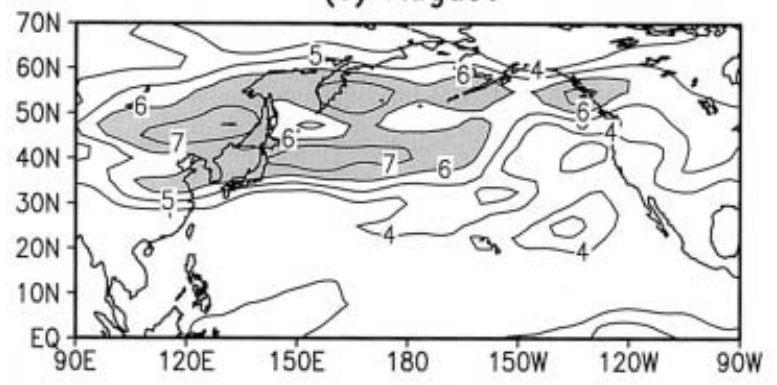

Fig. 9. Year-to-year standard deviation of 200-hPa zonal wind in June (a), July (b) and August (c). Contour interval is $1 \mathrm{~m} \mathrm{~s}^{-1}$, and the values larger than 6 are shaded. The contour lines lower than 4 are not shown for the sake of clarity.

basin, South Korea and southern Japan, and in August over the Huai River basin, Korea and central and southern Japan. This is true, even though identical two regions, for example, $\left(120-150^{\circ} \mathrm{E}, 40-50^{\circ} \mathrm{N}\right)$ and $\left(120-150^{\circ} \mathrm{E}, 30-\right.$ $40^{\circ} \mathrm{N}$ ), are used to depict the meridional displacement of EAJ for different months. This result is similar to the relationship between the poleward shifting suppressed convection along the East Asian rainy belt and the almost geographically fixed enhanced PSAC (Fig. 3). 


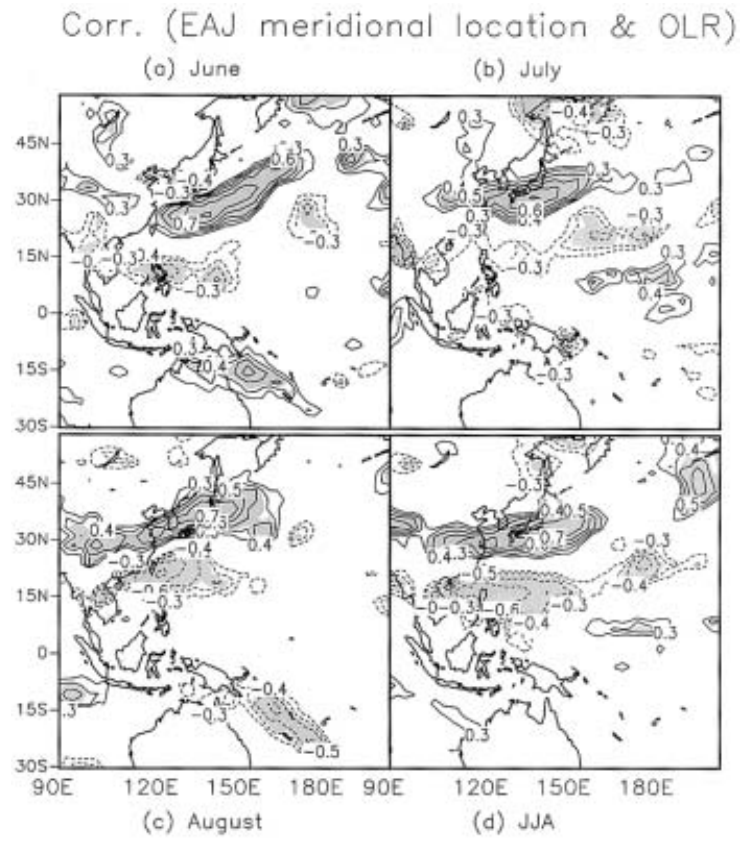

Fig. 10. Correlation coefficients between the EAJ meridional displacement and OLR at each grid point in June (a), July (b), August (c), and JJA (d). The EAJ meridional displacement is represented by the difference between the $200-\mathrm{hPa}$ zonal winds averaged at two regions that cover 10 degrees poleward and equatorward of the EAJ core within the longitudes of $120-150^{\circ} \mathrm{E}$ (poleward minus equatorward). The EAJ core is set to $37.5^{\circ} \mathrm{N}, 40^{\circ} \mathrm{N}, 45^{\circ} \mathrm{N}$ and $40^{\circ} \mathrm{N}$ for June, July, August and JJA, respectively. Contour interval is 0.1 , but the lines of $0, \pm 0.1$ and \pm 0.2 are not shown.

In addition, the enhanced convection over the tropical western Pacific also shifts poleward with month in Fig. 10.

Comparison between Figs. 8 and 10 suggests that in comparison with the intensity, the meridional displacement of EAJ has a more intimate relation with the East Asian summer convection. First, the correlation in Fig. 10 is higher than that in Fig. 8. Second, high correlation appears in all months in Fig. 10, but appears only in July and August with opposite signs in Fig. 8. Again, the relation between the EAJ meridional location and convection (indicated by OLR) tends to be helpful for the see- saw relationship in convective activity between the tropical western North Pacific and East Asia.

\section{Role of vertical shear of zonal wind on meridional associations}

In this section, we will investigate the possible reason for the significant sub-seasonal differences in the meridional associations in summer, which has been shown in the preceding section.

The area of the mid-latitude westerly in the upper troposphere extends further equatorward in June, which provides a condition more suitable for the Rossby wave propagation from the tropics to the mid-latitudes, compared with situations in July and August (Fig. 7). In the lower troposphere, on the other hand, the easterly occurs over the East China Sea and to the south of Japan, and thus the duct connecting tropics and middle latitudes is broken in August (Fig. 8b of Fukutomi and Yasunari 2002). Therefore, the sub-seasonal change in zonal wind in the subtropics is not likely to be the reason for the sub-seasonal differences in the meridional associations.

Tsuyuki and Kurihara (1989) showed that the tropical convection-midlatitude circulation relation exhibits a difference between the first and second half of summer. They found that the tropical convection is not strongly related to the midlatitude flow over East Asia at the first half of summer, while the convective activity around the Philippines and the Indo-China Peninsula has a significant impact on the East Asian atmospheric circulation at the second half of summer. Tsuyuki and Kurihara (1989) examined the atmospheric response to a specified vorticity source, and explained the difference in the tropical convection-midlatitude flow relation by the barotropic instability of climatological monthly mean $300-\mathrm{hPa}$ flow.

The present result is consistent with that of Tsuyuki and Kurihara (1989). However, we will present an alternative explanation through the role of the regional vertical shear of zonal wind in the tropics on the trigger of external modes. The vertical shear of zonal wind is not included in the barotropic model used by Tsuyuki and Kurihara (1989).

With the maximum in the midtroposphere, tropical latent heat release is internal, and by 
itself, inefficient in exciting external modes, which show the equivalent-barotropic structure and are thus necessary for the tropicalextratropical teleconnection mechanism. Using a simple two-level model, Lim and Chang (1986) found that vertical shear, differential damping and planetary boundary layer enable to transfer energy from internal mode to external mode, and vertical shear is normally the main effect for generating external mode. Kasahara and Silva Dias (1986) manifested that the vertical shear of zonal flows permits the coupling of external mode with internal mode, and a significant response of the external mode occurs in the extratropics. The external mode extends poleward and becomes predominant in the extratropics (Kato and Matsuda 1992; Wang and Xie 1996).

Figure 11 shows the vertical shear of climatological zonal wind over the tropical western Pacific. In all three months, the contour lines of zero are located over the tropical western Pacific, but they shifts eastward clearly in July and August. Thus, in July and August, the easterly shear is stronger than that in June over the tropical western Pacific. Over the region $\left(110-160^{\circ} \mathrm{E}, 10-20^{\circ} \mathrm{N}\right)$ chosen to represent the Philippine Sea, the vertical structure of zonal wind is roughly neutral in June, but exhibits an easterly shear in the following two months, particularly in August (Fig. 11d). The easterly shear in July and August permits the coupling of external mode with internal mode, and then the tropical-extratropical teleconnection.

The present explanation by vertical shear of zonal wind may obtain a support from the simulated results by Ose (1998), who studied the climatological seasonal evolution of the Asian summer monsoon circulation month by month, by examining the model response to the monthly zonal mean field and diabatic heat source. Note that zonal mean flow is used in the simulating study of Ose (1998). The vertical shear of zonal mean wind in the northern tropics, where the heat source in August is basically concentrated (e.g., Fig. 14c of Ose 1998), is roughly neutral in June but becomes easterly in July and August (not shown). Thus, the June flow in Ose's (1998) simulation would prevent large response in the extratropics, while the August flow would not. Ose's (1998) experi-

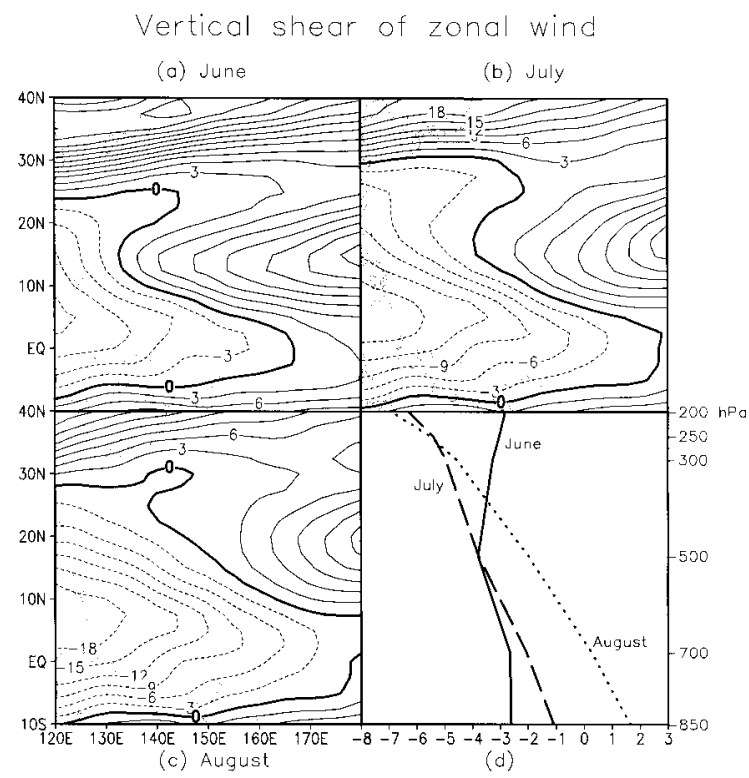

Fig. 11. The vertical shear $(200 \mathrm{hPa}$ minus $850 \mathrm{hPa}$ ) of climatological zonal wind in June (a), July (b) and August (c). (d) The vertical distribution of climatological zonal wind averaged over the Philippine Sea $\left(110-160^{\circ} \mathrm{E}, 10-\right.$ $20^{\circ} \mathrm{N}$ ) in each month of summer with the names of months along corresponding lines. That is, the solid, dashed and dotted lines are for June, July and August, respectively. Contour interval in (a), (b) and (c) is 3, and unit in the abscissa is in $\mathrm{m} \mathrm{s}^{-1}$ in (d).

ments showed that a replacement of the August zonal mean flow by the June one, while the diabatic heating remains unchanged, induces weaker monsoon circulation, such as southward shifted WNPSH due to a cyclonic anomaly over East Asia (his Fig. 19a). Since the heating source in August is related to stronger monsoon circulation (e.g., Figs. 18a and 18b of Ose 1998), the difference in vertical shear from June to August may be used to interpret the simulated result. Similarly, the Ose's (1998) simulated result caused by the change of zonal mean flow from June to July can also be interpreted.

The PSAC may affect convective activity in East Asia through the EAJ, as well as through the WNPSH. In June, the difference in PSAC is generally similar to that in July and August, at the aspects of both distribution and intensity, although the difference in the July PSAC 
is slightly weaker (Fig. 3). However, the associated convection difference over East Asia exhibits a clear change from month to month. Firstly, over East Asia, the June convection difference is weaker and not significant, while the convection differences in July and August occupy a larger region and are significant, particularly in August. Secondly, the suppressed convection exactly appears along the East Asian rainy belt in individual months. These two aspects of monthly difference are in a fairly good agreement with the monthly difference in the PSAC-EAJ relation, implying that the EAJ acts as a bridge between the PSAC and East Asian convective activities.

\section{Summary}

In this study, the NCEP/NCAR reanalysis circulation data and OLR data from 1979 to 1998 are used to examine the meridional coupling on the interannual timescale among the PSAC, WNPSH, East Asian convective activity and EAJ, which are all located over East Asia and the western Pacific. The meridional coupling in JJA and in each month of JJA is analysed, respectively, and compared each other.

On the interannual timescale, in each month and in JJA, the WNPSH all retreats eastwards significantly when the PSAC is enhanced, due to the negative 850 -hPa height anomalies in the tropical western Pacific that are expected as a consequence of the enhanced PSAC according to the theory of Gill (1980). The WNPSH also exhibits a slight poleward displacement, when the PSAC is enhanced.

The PSAC is strongly related to the EAJ and East Asian convection in July and August, but not in June. Although the 200-hPa zonal wind differences between strong and weak PSAC show a similar distribution in July and August, enhanced PSAC corresponds to a weakened EAJ in July but a strengthened EAJ in August due to the seasonal poleward shift of EAJ. In addition, the intensity of EAJ also shows different correlation patterns with the East Asian convection between July and August. A stronger EAJ corresponds to enhanced convection in East Asia in July but suppressed convection in August. Therefore, the seesaw pattern in convective activity between the Philippine Sea and East Asia rainy belt is strengthened by the PSAC-EAJ relation. On the other hand, the EAJ tends to exhibit a poleward displacement in July and August of enhanced PSAC. In each month of summer, a poleward displacement of EAJ is negatively correlated to the convection anomalies along the East Asian rainy belt.

The vertical shear of zonal wind over the Philippine Sea is possibly responsible for the sub-seasonal difference in the meridional coupling. The zonal wind over the Philippine Sea exhibits a roughly neutral vertical shear in June, but an easterly shear in the following two months. The easterly shear permits the coupling of external mode with internal mode, and a predominant response of the external mode in the extratropics (Kasahara and Silva Dias 1986; Lim and Chang 1986; Kato and Matsuda 1992; Wang and Xie 1996).

The present results suggest that anomalous PSAC induces East Asian rainfall anomaly through changing both the lower-level circulation in the subtropical western North Pacific (or the shape of WNPSH) and the upper-level circulation over East Asia, particularly the meridional displacement and intensity of EAJ. In each month, anomalous convection over the Philippine Sea is intimately associated with anomalous WNPSH. The PSAC-EAJ relation, however, is weak in June, but strong in the following two months. The EAJ acts as a bridge between the PSAC and East Asian convection in July and August. Therefore, this PSAC-EAJ relation is responsible for the monthly difference in the PSAC-East Asian convection relation.

\section{Acknowledgments}

The comments of two anonymous reviewers were extremely valuable in revising an earlier version of the manuscript. The author thanks Dr. B. Ailikun for her comments that were very helpful in clarifying the presentation. This study was supported by the National Natural Science Foundation of China under Grant 40075016 and Grant 40221503.

\section{References}

Fukutomi, Y. and T. Yasunari, 2002: Tropicalextratropical interaction associated with the 10-25-day oscillation over the western Pacific during the northern summer. J. Meteor. Soc. Japan, 80, 311-331. 
Gill, A.E., 1980: Some simple solutions for heatinduced tropical circulation. Quart. J. Roy. Meteor. Soc., 110, 203-217.

Gruber, A. and A.F. Krueger, 1984: The status of the NOAA outgoing longwave radiation data set. Bull. Amer. Meteor. Soc., 65, 958-962.

Huang, R.-H. and W.-J. Li, 1987: Influence of the heat source anomaly over the tropical western Pacific on the subtropical high over East Asia. Proc. International Conference on the General Circulation of East Asia. April 10-15, 1987, Chengdu, China, 40-51.

- and F.-Y. Sun, 1992: Impacts of the tropical western Pacific on the East Asian summer monsoon. J. Meteor. Soc. Japan, 70, 243256.

Kalnay, E. and Coauthors, 1996: The NCEP/NCAR 40-year reanalysis project. Bull. Amer. Meteor. Soc., 77, 437-471.

Kasahara, A. and P.L. Silva Dias, 1986: Response of planetary waves to stationary tropical heating in a global atmosphere with meridional and vertical shear. J. Atmos. Sci., 43, 18931911.

Kato, T. and Y. Matsuda, 1992: External mode induced by tropical heating in the basic flow with vertical shear and its propagation. J. Meteor. Soc. Japan, 70, 1057-1070.

Kurihara, K., 1989: A climatological study on the relationship between the Japanese summer weather and the subtropical high in the western North Pacific. Geophy. Mag., 43, 45-104. and M. Kawahara, 1986: Extremes of East Asian weather during the post ENSO years of 1983/84-Severe cold winter and hot dry summer. J. Meteor. Soc. Japan, 64, 493-503.

and T. Tsuyuki, 1987: Development of the barotropic high around Japan and its association with Rossby wave-like propagations over the North Pacific: Analysis of August 1984. J. Meteor. Soc. Japan, 65, 237-246.

Liang, X.-Z. and W.-C. Wang, 1998: Associations between China monsoon rainfall and tropospheric jets. Quart. J. Roy. Meteor. Soc., 124, 2597-2623.
Lim, H. and C.-P. Chang, 1986: Generation of internal- and external mode motions from internal heating: Effects of vertical shear and damping. J. Atmos. Sci., 43, 948-957.

Lu, R., 2001: Atmospheric circulations and sea surface temperatures related to the convection over the western Pacific warm pool on the interannual scale. Adv. Atmos. Sci., 18, 270-282. , 2002: Indices for the summertime western North Pacific subtropical high. Adv. Atmos. Sci., 19, 1004-1028.

and B. Dong, 2001: Westward extension of North Pacific subtropical high in summer. $J$. Meteor. Soc. Japan, 79, 1229-1241. , 1987: Convective activities in the tropical western Pacific and their impact on the northern hemisphere summer circulation. J. Meteor. Soc. Japan, 65, 373-390.

, T. Maruyama and T. Motoki, 1986: Longterm variations of tropospheric circulations in the western Pacific region as derived from GMS cloud winds. J. Meteor. Soc. Japan, 64, 895-911.

Ose, T., 1998: Seasonal change of Asian summer monsoon circulation and its heat source. $J$. Meteor. Soc. Japan, 76, 1045-1063.

Tao, S.Y. and L.X. Chen, 1987: A review of recent research on the East Asian summer monsoon in China, Review in Monsoon Meteorology, Oxford Univ. Press, 60-92.

Tsuyuki, T. and K. Kurihara, 1989: Impact of convective activity in the western tropical Pacific on the East Asian summer circulation. J. Meteor. Soc. Japan, 67, 231-247.

Wang, B., R. Wu and K.-M. Lau, 2001: Interannual variability of the Asian summer monsoon: Contrasts between the Indian and the western North Pacific-East Asian monsoon. J. Climate, 14, 4073-4090. - and X. Xie, 1996: Low-frequency equatorial waves in vertically sheared zonal flow. Part I: Stable waves. J. Atmos. Sci., 53, 449-467.

Wu, R. and B. Wang, 2001: Multi-stage onset of the summer monsoon over the western North Pacific. Clim. Dyn., 17, 277-289. 